\title{
Improvement of Teacher Innovation through Development of Organizational Culture, School Head Supervision, and Achievement Motivation
}

\author{
Nendi Nuradin*, Billy Tunas, Widodo Sunaryo \\ Postgraduate Program, Pakuan University Bogor, Indonesia
}

*Corresponding Author: Nendi Nuradin, Postgraduate Program, Pakuan University Bogor, Indonesia

\begin{abstract}
This study aims to improve teacher innovation through improving organizational culture, supervision of school principals and achievement motivation on permanent teachers in Islamic Primary School in Bogor Regency by using a mixed research method with sequential explanatory where at the first stage of research is carried out using quantitative methods and in the second stage is carried out with qualitative methods to deepen and expand the research results. Further, Scientific Identification Theory of Operation Research in Education Management (SITOREM) is used to rank the improvement needed. The population of the study was the teachers at integrated Islamic primary school in Bogor Regency totaling 459. The study sample was 214 respondents determined by using the Taro Yamane formula. Sampling is done by proportional random sampling. Qualitative data is collected through interviews, observation, and documentation. The results of the quantitative research of this study are: 1) There is a positive relationship between organizational culture and teacher innovation 2) There is a positive relationship between supervision of the principal and teacher innovation 3) There is a positive relationship between achievement motivation and teacher innovation, and finally, 4) there is a positive relationship between organizational culture, supervision of principals and achievement motivation together with teacher innovation. The results of the quantitative research supported the results of qualitative research on each research variable. Based on these findings, the stronger the organizational culture, supervision of principals and achievement motivation, the higher the innovation among teachers.
\end{abstract}

Keywords: Organizational Culture, Supervision of the Principal, Achievement Motivation, Teacher Innovation

\section{INTRODUCTION}

Teachers, as the agent of education, are required to have professional abilities in planning and carrying out the learning process, assessment of learning outcomes, and guidance and training of students. Needed Innovation is so that this critical responsibility can work as it should. Innovative teachers who can reach competency standards even surpass them. Teachers who have innovations tend to follow updates or changes to a better direction that supports the optimization of the implementation of their duties. Innovative teachers plan to learn carefully, read and review the learning resources to be used, analyze necessary competencies up to the preparation of the Learning Implementation Plan. With proper planning, the teacher will be able to display performance teaching that can develop student innovation and create learnin $\backslash \mathrm{g}$ that is active, creative, effective, exciting, and fun.

Based on background conditions, theoretical studies and reasoning of researchers, teacher innovation is thought to be influenced by organizational culture both in the school itself and the corporate culture at the education service level as a controlling element of the education process in the region. Organizational culture is a shared belief, norms, and values that are characteristic of how to do things in an organization. These beliefs, rules, and values are a guide and encouragement for all school members to carry out various innovative activities. In addition to organizational culture, school principal supervision activities are allegedly related to teacher innovation. Supervision is one of the professional service activities in the form of assisting teachers in improving the ability to implement changes in a better direction. Achievement motivation is also related to teacher innovation in learning. Motivation is the primary drive that moves a person to behave. Achievement motivation is the desire or needs in a teacher to achieve the best results 
From many things that are thought to have a relationship with teacher innovation, this study limits to finding the strength of the relationship of innovation with organizational culture, supervision of principals and achievement motivation. Based on the background described previously, then the formulation of the problem in this research variable is:

- Is there a relationship between organizational culture and teacher innovation?

- Is there a relationship between supervising the principal and the innovation of the teacher?

- Is there a relationship between achievement motivation and teacher innovation?

- Is there a relationship between organizational culture, principal school supervision, and achievement motivation together with teacher innovation?

\section{LITERATURE REVIEWS}

Schools have moved to an innovation era requiring adjustment in the practice in teaching and learning (Abbas et al., 2018). According to Suharyati (2017), innovation is the process of making changes to something already established by introducing something new, the successful implementation of creative ideas within an organization. Innovation is a process of making changes from something that has been formed into something new. The indicators are a. product innovation which includes innovation on products or commodities produced/operated, b. Service innovation, including innovation about relationships with customers, c. Process innovation that provides for methods, procedures or techniques for procurement of products/services, d. Marketing innovation, including innovation in promotional and sales activities, e. business innovation, including business development or expansion activities, and f. organizational innovation that includes innovation in governance and management.

Baer (2003) states that innovation is the act of processing a new idea to be realized into something practical. The indicators are a. product innovation, namely goods, new products or services, and $\mathrm{b}$ process innovation, which is a new procedure or way of working.

Colquitt (2009) defines organizational culture as recognized social knowledge in an organization, including rules, norms, and values that shape the attitudes and behavior of all employees. Organizational culture as the shared social knowledge has an organization regarding the rules, norms, and values that shape the attitudes and behaviors of its employees. Indicators are a. Social knowledge among members of the organization, b. Rules, norms, and values in the organization, and c. Form and strengthen the attitudes and behavior of members of the control system provisions of all members of the organization. According to Alveson (2015), organizational culture is a pattern of underlying assumptions, which are formed, materialized and developed by organizational members to repeat the problems of adaptation to external factors and to integrate factors internal organization factors. Dimensions and indicators are a. Behavior and work including methods, art, technology in action, and patterns of real practice, $b$. Values are values of the environment, and norms agreed upon by members, $\mathrm{c}$ - models of underlying assumptions including relationships with the environment, views on humanity, and relationships between individuals.

Caspi (2002) defines supervision as examining the work of others by the supervisor who is authorized to monitor performance directly and ensure satisfactory performance. Supervision is an activity overseeing the process and results of one's work and controlling the work so that it can obtain satisfactory results. Hendrison (2006), suggest that supervision is an activity of observing, directing, predicting, and investigating. Successful supervision requires conventional and suitable ways to perform. The indicators are a. more collegial relations than the hierarchy between teachers and supervisors, b. Supervision as a formally designed area of teachers and supervisors, c focusing on teacher growth, not on workers, d. Facilitating teachers collaborating with each teaching improvement effort, and e. teacher involvement in the process of receiving identity.

Koesmono (2015) state that the need for achievement is formulated as achieving something difficult, doing something as quickly and independently as possible, competing and outperforming others, increasing self-esteem through training successful talents. The indicators are a. selecting to do tasks with moderate difficulty, b. selecting a situation whose performance is measured by business rather than by other factors such as luck, and c - expecting more feedback on success and failure. 
According to Brown (2005), the need for achievement is the need to do something better, solve problems or complicated master tasks. The indicators are a. the need to do something better and more efficiently, $b$. The need to solve problems, and c. The need to master complicated things.

From the basics theory above, the hypothesis for this research are :

- There a relationship between organizational culture and teacher innovation

- There a relationship between supervising the principal and the innovation of the teacher

- There a relationship between achievement motivation and teacher innovation

- There a relationship between organizational culture, principal school supervision, and achievement motivation together with teacher innovation

\section{METHODS}

This study was conducted at Integrated Islamic Primary School in Bogor Regency, originating from 22 schools. The entire study was conducted from June 2017 to June 2018. This study uses a sequential explanatory mixed method. The population of this study was a permanent teacher of the Integrated Islamic Primary School foundation in Bogor Regency, totaling 459 people. Sampling uses proportional random sampling technique. Determination of the number of samples using the Taro Yamane formula to obtain a sample of 214. Quantitative data collection uses a survey with an instrument questionnaire distributed to respondents. In the qualitative stage, to prove, deepen, and expand quantitative research data carried out through observation, interviews, focus group discussions (FGD) and documentation studies, namely examining, observing documents relating to Teacher Innovation, Organizational Culture, Principal Supervision, and Achievement Motivation. Moreover, Scientific Identification Theory of Operation Research in Education Management (SITOREM) is used to determine the rank.

The constellation of research variables illustrates the relationship between Organizational Culture, Principal Supervision, and Achievement Motivation with Innovation can be described as follows:

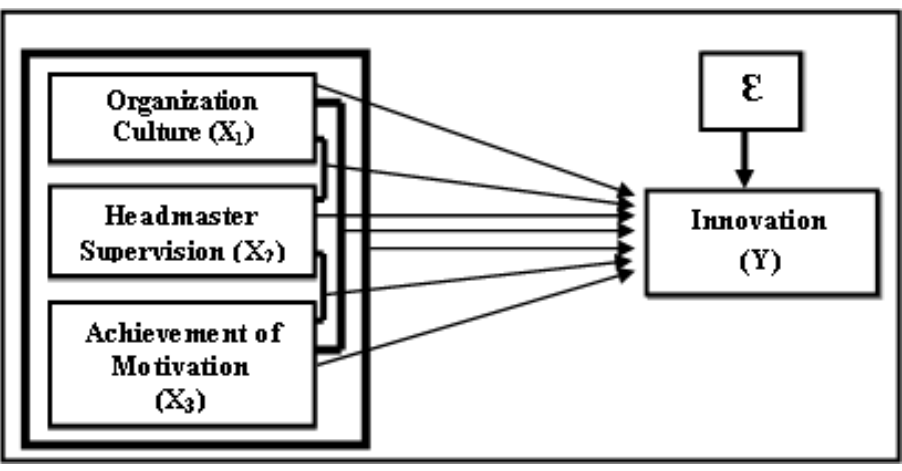

Figure1. Constellation of Research Variables

Description: $\mathrm{X}_{1}$ : Organizational Culture, $\mathrm{X}_{2}$ : Principal Supervision, $\mathrm{X}_{3}$ : Achievement Motivation, $\mathrm{Y}$ : Innovation, $\mathcal{E}$ (epsilon): Other variables related

\section{RESUltS AND DiSCUSSION}

\subsection{Relationship between Organizational Culture and Teacher Innovation}

The results of this study indicate that there is a positive relationship between organizational culture and the innovation of teachers with the regression equation $\hat{\mathrm{Y}}=32.36+0.86 \mathrm{X}_{1}$. The resulting correlation coefficient of 0.8188 shows that each increase in organizational culture will increase the innovation of the teacher, and the coefficient of determination $\mathrm{r}_{\mathrm{y} 1}{ }^{2}=0.6704$. This means that $67.04 \%$ of teacher innovation is a result of the workings of organizational culture, while $32.96 \%$ is contributed by other variables that have a relationship with teacher innovation. The findings obtained in this study identify that organizational culture is the teacher's perception of a set of underlying assumptions and values that are understood and implemented by the teachers, and are valuable to be taught to new teachers to perceive, think, and feel related to completion problems related to the duties and functions of the teacher at school. 
Improvement of Teacher Innovation through Development of Organizational Culture, School Head Supervision, and Achievement Motivation

Table1. Relationship between organizational culture $\left(X_{1}\right)$ to teacher's innovation $(Y)$

\begin{tabular}{|c|c|c|c|c|c|}
\hline Observation & $\mathbf{R}$ & $\mathbf{R}^{2}$ & $\mathbf{F}_{\text {-test }}$ & $\mathbf{F}_{\text {-table }} \alpha$ & \multirow{2}{*}{ Conclusion } \\
\cline { 1 - 4 } $\mathbf{N}$ & $\mathbf{R}_{\mathbf{x} 1}$ & $\mathrm{r}^{2}{ }_{\mathbf{x} 1}$ & $\mathbf{F}_{\mathbf{x} 1}$ & 0.05 & Significant \\
\hline 214 & 0.818 & 0.670 & 20.79 & 0.42 & \\
\end{tabular}

The results of interviews, FGDs, observations, and documentation in the three Integrated Islamic Primary School of Bogor Regency, it can be seen that there is a tendency for relations between organizational culture and teacher innovation. This shows that there is a strengthening of the results of qualitative research on quantitative research results of hypothesis testing which states that there is a positive functional relationship between organizational culture and the innovation of teachers.

Based on the results of the SITOREM analysis, an illustration shows that the underlying assumption pattern has the essential meaning and ranks first at $25 \%$ with an empirical finding of an average of 5.82. Behavior patterns and results of work occupy the second rank of 34\%, with empirical findings averaging 5.96. While the design of values ranks third, which is $41 \%$ with an average empirical result of 6.05. The three indicators of organizational culture have a strong relationship with innovation. This means that the stronger the organizational culture, the higher the innovation of the teacher. In line with the results of a research study by Gumuslugu (2009), Organizational culture has a positive relationship with teacher innovation. In the analysis obtained the results of regression analysis showed that organizational culture has a strong relationship with teacher innovation. Therefore when implementing organizational culture, all teachers must strengthen shared values to increase the success of teacher innovation.

\subsection{The Relationship between Supervising the Principal and Teacher Innovation}

The results showed that there was a positive relationship between the supervision of the principal and the innovation of the teacher with the regression equation $\hat{Y}=91.22+0.53 \mathrm{X}_{2}$. The resulting correlation coefficient of 0.4996 shows that an increase in the school supervisor's score will increase teacher innovation and the coefficient of determination $\mathrm{r}_{\mathrm{y} 2}{ }^{2}=0.2496$. This means that $24.96 \%$ of teacher innovation is the result of the work of the principal's supervision, while $75.04 \%$ is contributed by other variables that have a relationship with increasing teacher innovation. The findings obtained in this study identify that the supervision of the principal is the attitude of the teacher based on the evaluation of what is felt in carrying out the work.

Table 2. The relationship between Supervising $\left(X_{2}\right)$ to teacher's innovation $(Y)$

\begin{tabular}{|c|c|c|c|c|c|}
\hline Observation & $\mathbf{R}$ & $\mathbf{R}^{2}$ & $\mathbf{F}_{\text {-test }}$ & $\mathbf{F}_{\text {-table }} \alpha$ & \multirow{2}{*}{ Conclusion } \\
\cline { 1 - 4 } $\mathbf{N}$ & $\mathbf{R}_{\mathbf{x} 2}$ & $\mathrm{r}^{2}{ }_{\mathbf{x} 2}$ & $\mathbf{F}_{\mathbf{x} 2}$ & 0.05 & \\
\hline 214 & 0.496 & 0.249 & 11.4 & 0.42 & Significant \\
\hline
\end{tabular}

The results of interviews, FGDs, observations, and documentation, it can be seen that there is a tendency for the relationship between the supervision of the principal and the teacher's innovation. This shows that there is a strengthening of quantitative research results of hypothesis testing stating that there is a positive relationship between supervising principals and the innovation of teachers with regression is very significant and shows that an increase in school principals' supervision scores will increase teacher innovation.

Based on the results of the SITOREM analysis there is a relationship between the supervision of the principal and the innovation of the teacher, and it can be seen that the performance evaluation has an essential meaning with the first rank of $18 \%$ with empirical findings of 5.88. Coaching has a critical sense for the second place, namely $24 \%$ with an average empirical outcome of 5.95. Professional training has an essential meaning in the third place, which is $27 \%$ with an average empirical finding of 6.02 whereas monitoring has a fundamental sense by occupying the fourth rank which is equal to $31 \%$ with an average empirical result of 6.05 . All indicators of supervision of the principal have a strong relationship with the innovation of the teacher. This means that the stronger the supervision of the principal, the higher the innovation of the teacher.

\subsection{The Relationship between Achievement Motivation and Teacher Innovation}

The results showed that there was a positive relationship between achievement motivation and the innovation of teachers with the regression equation $\hat{Y}=56.97+0.72 X_{3}$. The resulting correlation 
Improvement of Teacher Innovation through Development of Organizational Culture, School Head Supervision, and Achievement Motivation

coefficient of 0.7425 shows that every increase in the score of achievement motivation will increase the innovation of the teacher, and the coefficient of determination between achievement motivation and teacher innovation is $\mathrm{R}_{\mathrm{y} 3}{ }^{2}=0.5513$. This means that $55.13 \%$ of teacher innovation is the result of the achievement of achievement motivation, while $44.87 \%$ is contributed by other variables that have a relationship with increasing teacher innovation.

Table3. The relationship between Achievement Motivations $\left(X_{3}\right)$ to teacher's innovation $(Y)$

\begin{tabular}{|c|c|c|c|c|c|}
\hline Observation & $\mathbf{R}$ & $\mathbf{R}^{\mathbf{2}}$ & $\mathbf{F}_{\text {-test }}$ & $\mathbf{F}_{\text {-table }} \alpha$ & \multirow{2}{*}{ Conclusion } \\
\cline { 1 - 4 } $\mathbf{N}$ & $\mathbf{R}_{\mathbf{x} 3}$ & $\mathbf{r}_{\mathbf{x} 3}^{2}$ & $\mathbf{F}_{\mathbf{x} 3}$ & 0.05 & \\
\hline 214 & 0.7425 & 0.5513 & 22.08 & 0.42 & Significant \\
\hline
\end{tabular}

Based on the results of interviews, FGDs, observation, and documentation in the three Integrated Islamic Primary School of Bogor Regency, it can be seen that there is a tendency for the relationship between achievement motivation and teacher innovation. This shows that there is a strengthening of quantitative research results of hypothesis testing stating that there is a functional relationship between achievement motivation and the innovation of teachers with regression is very significant and shows that an increase in achievement motivation will increase teacher innovation.

Based on the results of the SITOREM analysis, it was obtained an illustration that, the drive to excel in the competition had an essential meaning with the first rank of $18 \%$ with an empirical finding of an average of 5.58. Working intensively in carrying out assignments has the importance of occupying the second rank which is equal to $18 \%$ with empirical results averaging 5.67. The desire to achieve the stated goals has an essential meaning in the third place, which is $18 \%$ with an average empirical finding of 5.70. Resolving problems has the importance of occupying the fourth place at $18 \%$ with an average empirical result of 5.71. Strong desire to get feedback on performance has an essential meaning in fifth place at $14 \%$ with an average empirical finding of 5.76. While the need for successful work in the long term has a significant meaning and ranks sixth which is equal to $14 \%$ with empirical results on average 5.81 .

\subsection{The Relationship between Organizational Culture, School Principal Supervision and Achievement Motivation Together with Teacher Innovation.}

The results showed that there was a functional relationship between organizational culture, supervision of the principal and achievement motivation together with the innovation of the teacher with the regression equation $\hat{\mathrm{Y}}=19.75+0.62 \mathrm{X}_{1}+0.02 \mathrm{X}_{2}+0.28 \mathrm{X}_{3}$ very significant. The multiple correlation coefficient between organizational culture, principal school supervision and achievement motivation together with teacher innovation of 0.8404 shows that an increase in organizational culture scores, school primary supervision, and achievement motivation together will increase teacher innovation. The results obtained for the determination coefficient $t_{1.2 .3}{ }^{2}$ from the correlation between organizational culture, principal supervision, and achievement motivation together with teacher innovation amounted to 0.7063 . This means that $70.63 \%$ of teacher innovation is the result of the workings between organizational culture, school principal supervision and achievement motivation together, while $29.37 \%$ is contributed by other variables that have a relationship with increasing teacher innovation.

SITOREM analysis as proposed by as postulated by Hardhienata (2017) is presented in Figure 1.

The results showed that the correlation coefficient was higher if the three variables, namely organizational culture, school principal supervision and achievement motivation together with teacher innovation, namely the correlation coefficient between organizational culture and supervision of principals ry $1.2=0.8392$, correlation coefficient between principal supervision and achievement motivation ry $2.3=0.7573$ and the correlation coefficient between organizational culture and achievement motivation ry $1.3=0.8402$. This implies that organizational culture, supervision of the principal and achievement motivation together are factors in achieving teacher innovation more optimally.

Based on interviews, FGDs, observations, and documentation in the three Integrated Islamic Primary School of Bogor Regency, it can be seen that there is a tendency for relations between organizational culture, school principal supervision and achievement motivation together with teacher innovation. This shows the strengthening of quantitative research results of hypothesis testing stating that there is 
a functional relationship between organizational culture, principal supervision and achievement motivation with the innovation of teachers with regression is very significant and shows that an increase in organizational culture scores, supervision of principals and achievement motivation will increasing teacher innovation.

$\mathrm{r}_{\mathrm{vl}}=0.819$

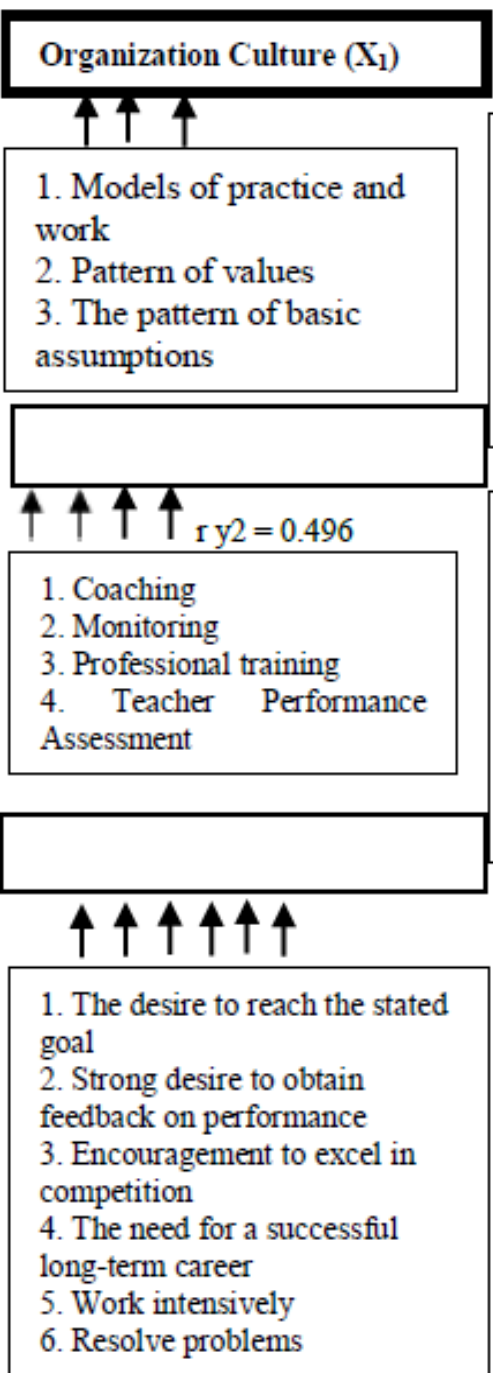

WEIGHT

1. Patterns of values

(41) (6.05)

2. Patterns of behavior

and work (34) (5.96)

3. The pattern of basic assumptions (25)

(5.82)

WEIGHT

1. Monitoring (30)

(6.03)

2. Professional training

(27) (6.2)

3. Coaching (24) (5.95)

4. Teacher

Performance

Assessment (18) (5.88)

WEIGHT

1. Encouragement to excel (18) (5.58)

2 . Working intensively

(18) (5.67)

3 . The desire to

achieve goals (18) (5.7)

4. Resolve the problem

(18) (5.71)

5 . Willingness to get

feedback $(14)(5,76)$

6 . Success needs (14)

(5.81)

Ry $3=0.742$

\begin{tabular}{|l|}
\hline \\
\hline 1. Product innovation \\
2. Process Innovation \\
3. Service Innovation \\
4. Management \\
\hline
\end{tabular}

\section{WEIGHT}

1. Product innovation

(40) (5.96)

2. Service innovation

(30) (6.03)

3. Organizational

innovation (15) (5.58)

4. Process innovation

(15) (5.92)
PRIORITIES:

1. Patterns of values (41) (6.05)

2. Patterns of behavior and work

(34) (5.96)

3 . The pattern of basic

assumptions (25) (5.82)

4. Encouragement to excel (18)

(5.58)

5. Work intensively (18) (5.67)

6 . The desire to achieve goals

(18) (5.7)

7. Resolve the problem (18)

(5.71)

8. Willingness to get feedback

(14) (5.76)

9. Need for success (14) (5.81)

10. Monitoring (30) (6.03)

11. Professional training (27)

(6.2)

12. Coaching (24) (5.95)

13. Teacher Performance

Assessment (18) (5.88)

14. Product innovation (40)

$(5.96$

15. Service innovation (30)

$(6.03$

16. Organizational innovation

(15) $(5.58$

17. Process innovation (15)

(5.92)

Figure1. SITOREM Analysis

From the findings obtained in this quantitative research phase, it can be seen that $70.63 \%$ of teacher innovation is the result of the work of organizational culture, supervision of principals and achievement motivation together so that it can be estimated that other variables contribute $29.37 \%$. From the results of interviews, several factors that are considered to be related to the innovation of teachers include job satisfaction factors, principals' leadership, organizational citizenship behavior (OCB), organizational work climate, entrepreneurship, rewards, and work commitments, estimated to be related to contributing increasing teacher innovation. 


\section{CONCLUSION}

There is a highly real strength of the relationship between organizational culture, and teacher innovation can be identified, with a correlation of $67.04 \%$. Thus the higher the organizational culture, the higher the level of innovation of the teacher. There is a highly positive relationship between supervision of principals with teacher's innovation, with a correlation of $24.96 \%$. Thus, the higher the supervision of the principal, the higher the teacher's innovation. There is a highly positive relationship between supervision of principals with teachers innovation, with a correlation of $55.13 \%$. Thus, the higher the supervision of the principal, the higher the teacher's innovation. There is a highly positive strength of a relationship between organizational culture, principal school supervision and achievement motivation together with teacher innovation, with a correlation $70.63 \%$ and an estimated $29.37 \%$ contributed by other variables that have a relationship with increasing teacher innovation. Based on interviews, FGDs, observations, and documentation at three Integrated Islamic Primary School in Bogor Regency, it can be seen that there is a tendency for the relationship between organizational culture, principal supervisions and achievement motivation to teacher innovation that reinforces the results of quantitative research.

\section{REFERENCES}

[1] Abbas, E. W., S. Hadi, and I. Rajiani. "The prospective innovator in public university by scrutinizing particular personality traits." Polish Journal of Management Studies 18 (2018).

[2] Alvesson, Mats, and Stefan Sveningsson. Changing organizational culture: Cultural change work in progress. Routledge, 2015.

[3] Baer, Markus, and Michael Frese. "Innovation is not enough: Climates for initiative and psychological safety, process innovations, and firm performance." Journal of Organizational Behavior: The International Journal of Industrial, Occupational and Organizational Psychology and Behavior 24, no. 1 (2003): 45-68.

[4] Brown, Michael E., Linda K. Treviño, and David A. Harrison. "Ethical leadership: A social learning perspective for construct development and testing." Organizational behavior and human decision process 97, no. 2 (2005): 117-134.

[5] Caspi, Jonathan, and William J. Reid. Educational supervision in social work: A task-centered model for field instruction and staff development. Columbia University Press, 2002.

[6] Colquitt, Jason A., Donald E. Conlon, Michael J. Wesson, Christopher OLH Porter, and K. Yee Ng. "Justice at the millennium: a meta-analytic review of 25 years of organizational justice research." Journal of applied psychology86, no. 3 (2001): 425.

[7] Gumusluoğlu, Lale, and Arzu Ilsev. "Transformational leadership and organizational innovation: The roles of internal and external support for innovation." Journal of Product Innovation Management 26, no. 3 (2009): 264-277.

[8] Hendricson, William D., Sandra C. Andrieu, D. Gregory Chadwick, Jacqueline E. Chmar, James R. Cole, Mary C. George, Gerald N. Glickman, et al. "Educational strategies associated with the development of problem-solving, critical thinking, and self-directed learning." Journal of Dental Education 70, no. 9 (2006): 925-936.

[9] Koesmono. "Influence of the Factors of Personality, Motivation, Job Satisfaction to the Organizational Commitment and Influence of Motivation, Job Satisfaction, Organizational Commitment to Performance of Broadcaster of National Private Radio Broadcast in Surabaya." European Journal of Business and Management ISSN (2015): 2222-1905.

[10] Suharyati, Henny. "Interaction of Relationship between Job Motivation with Teacher Innovativeness in Improving Education." JETL (Journal Of Education, Teaching and Learning) 2, no. 2 (2017): 228-232.

Citation: Nendi Nuradin, et.al. "Improvement of Teacher Innovation through Development of Organizational Culture, School Head Supervision, and Achievement Motivation" International Journal of Managerial Studies and Research (IJMSR), vol 7, no. 4, 2019, pp. 47-53. doi: http://dx.doi.org/10.20431/ 2349-0349.0704007.

Copyright: (C) 2019 Authors. This is an open-access article distributed under the terms of the Creative Commons Attribution License, which permits unrestricted use, distribution, and reproduction in any medium, provided the original author and source are credited. 